\title{
Back and Forth of Open Innovation: Outstanding Issues and Future Research Works ${ }^{1}$ Andy Susilo Lukito-Budi Universitas Katolik Atma Jaya Jakarta, Indonesia
}

\section{Abstract}

This paper reviews the concept of open innovation compared to closed innovation. It starts with contrasting two papers about open innovation and discusses point of view from both papers and reveals outstanding issues from them. This paper continues with presenting issues about open innovation from various angles, such as classical organizational mechanism and theory, funding and commercialization, collaboration and intermediary agent role, as well as security and good governance conduct practice. Throughout the discussion process, it appeared some issues have been confirmed while some issues are still in large debate. This paper summarizes the unresolved issues into several potential research theme to be investigated further.

Keywords: closed innovation, future research work, innovation topics, open innovation, open issues

JEL $\quad$ : O36

DOI : 10.24002/kinerja.v22i2.3226

Received : 08/30/2019 Reviewed: 10/28/2019 Final Version: 11/20/2019

\section{INTRODUCTION}

Open innovation (OI) was firstly introduced by Chesbrough (2003) by giving some arguments why companies could no longer survive in a closed innovation (Cl) $\mathrm{He}$ argued $\mathrm{Ol}$ was triggered by an increasing mobility of knowledge workers who could move anywhere so that companies ${ }^{1}$ found difficulties to control their proprietary knowledge. As a result, the player in the Ol extended from R\&D workers to knowledge workers (Kach et al. 2015) which was broader. He presented his concept supported by six principles that segregate $\mathrm{Ol}$ with $\mathrm{Cl}$. Chesbrough (2003) said that in OI, an organization commercialized its original idea together with innovation from other organizations and find out how to market by applying the path beyond its current business. He also notified that border line between the

\footnotetext{
${ }^{1}$ This paper uses the word organization and company interchangeably. The word companies refer to business organizations while the word organizations refer to more generic meaning of any institution, including nonprofit organizations.
} 
company and its environment (other organizations) became blur as shown in dotted lines representing the interconnection between organization and its externalities as well as marking the difference between $\mathrm{Cl}$ and $\mathrm{Ol}$. Since then, the Ol concept was widely used in research works and it was accepted as one important concept in innovation theme.

Trott \& Hartmann (2009) gave critics to the OI, and they even portrayed the OI concept as "old wine" in a new bottle. Their main argument was based especially in the roots of the six principles proposed by Chesbrough (2003). Interestingly, they finally concluded to support the development of the Ol concept despite the criticism. This was due to the shift of changes in strategic view about innovation and changing the direction would be very expensive and futile. In its establishment, Ol principles had been used to cultivate collaboration between companies/organizations and their externalities (Shin et al. 2016; Un \& Asakawa 2015). In light of that, discussing the Ol concept, reviewing its establishment to the current, and analyzing its relevance to the organizations would be interesting. This paper also extended the work from Hossain (2013) which also had explored OI concept and implementation at that time.

This paper aimed to review both papers from Chesbrough (2003) and Trott \& Hartmann (2009). This paper used these two papers simultaneously due to their interconnected ideas simultaneously. This conceptual paper compared and contrasted the works of Chesbrough (2003) and Trott and Hartmann (2009) focusing on the six $\mathrm{OI}$ principles. It detailed the $6^{\text {th }}$ principles differentiating $\mathrm{Ol}$ and $\mathrm{Cl}$ from them. The discussion would start by stating the position of this paper and addressed some concerns raised by them in the current situation.

Furthermore, this paper reviewed more recent papers from various topics of innovation. It linked and related the findings on the papers with concerns raised from Chesbrough (2003) and Trott and Hartmann (2009) papers. It explored findings and identified some potential issues to be followed with further research. Finally, all the ongoing issues were summarized and presented in relation to OI issues. Limitation about empirical works on this paper also acknowledged at the end of this paper.

\section{LITERATURE REVIEW}

In his paper, Chesbrough (2003 p. 36-37) defined open innovation as a model where "companies can commercialize internal ideas through channels outside of their current businesses in order to generate value for the organization." The root of Ol was abundance of knowledge surrounding companies and they should use and make advantages out of it. Hence companies should not restrict the flow of external knowledge that potentially brought advancement into current organization business processes nor should only to bring company's internal knowledge into the 
market. Companies that relied heavily on internal was prone to miss opportunities from its externalities.

Chesbrough (2003) summarized the differences between $\mathrm{Cl}$ and $\mathrm{Ol}$ into six principles. These six principles were argued to be the main heart of Ol philosophy. First, he stated not every smart person worked for companies. Hence, brilliant person must be sought from outside, used the knowledge and the brain in favor of the company. Second, although R\&D was still important, he argued that its role was not as central as in $\mathrm{Cl}$. Moreover, it was believed that R\&D from external companies could create significant value. Third, to earn profit, companies did not have to reinventing the wheel. Instead, they could use the accumulation of knowledge from external and took advantage out of it. This was contrasting with $\mathrm{Cl}$ that promoted originality of discovery to ensure dominance in the market. Fourth, Ol considered that built a better business model first before entering the market was more important than commercialize to the market as believed in $\mathrm{Cl}$. In $\mathrm{OI}$, the goal was not to be a pioneer of one innovation but took the most benefit of the innovation (not just exploration but also exploitation). Fifth, by fully utilized ideas from internal and external companies, it was most likely the company would win the competition. In contrast, $\mathrm{Cl}$ considered the best idea should be developed internally. Sixth, OI stated companies should be able to take advantage of the use of intellectual property rights (IPR) of others, and, if necessary, bought it when the IPR had the potential to advance the companies' business model. $\mathrm{Cl}$, on the other hand, relied on control over company's intellectual properties so that competitors could not take advantage over them.

Six years later after its first introduction, Trott \& Hartmann (2009) presented some objections to the six principles. While they did not reject the idea of the $6 \mathrm{OI}$ principles, they argued the opposites (i.e. Cl principles) as claimed in contrast with the Ol principles were not entirely correct. First, they argued that the concept of "brilliant person must be sought from outside" was not solely intended to the OI. In fact, some researchers had recognized the existence of knowledge from outside prior the Ol era (Nonaka 1991). Second, they notified that some alliances had been established long before OI emerged. For example, alliances between allied airbus to compete with Boeing and McDonnell Douglas, Phillip-LG, Sony-Ericsson, etc. They also pointed out that $\mathrm{Ol}$ was overlook all research efforts in knowledge transfer and absorptive capacity, of which they emphasized the importance of R \& $D$ functions so that the organization could still benefit from the use of external technology. Third, they found out that the industrial R\&D landscape was full of contrasting evidence to the concept of $\mathrm{Cl}$ promoted originality of discovery. They gave example of Corning glass that benefited from alliance with PPG due to access to new market and new opportunity. They stated that R\&D had dramatically changed over the past 20 years due to three critical factors, i.e.: (1) technology explosion, (2) technology cycle was shorter, (3) technology globalization. Fourth, they presented some cases showing companies had recognized that innovation success was more than being the first in the market. They mentioned some 
strategies that also had been proven useful, such as monopoly (specifically in technology dominance), leader/offensive, fast follower/defensive, and cost minimization/imitative, market segmentation. Fifth, they claimed the development of idea from internal R\&D seemed too subjective and biased when it related to $\mathrm{Cl}$. In many instances a technology was well established because it was interesting. The better approach was to enhance ability to capture idea from R\&D and convert the idea into real useful product (or services). Lastly, they stated to control company's IP was unreasonable. History stated that license exchange happened overtime, secure joint venture had licensed its IP over many vendors, etc. These actions happened due to mutual interest among corporations, and acquiring licensed technology was not as easy as it seemed.

Trott \& Hartmann (2009) stated that the dichotomy of "closed" and "open" words very often was wrongly interpreted and used. While the dichotomy may work theoretically, it did not really apply in industry. Nevertheless, they notified that the false dichotomy could be used to spread important messages across to emphasize the new and better concepts compared to the previous one. It simplified the innovation concept into two extreme points $A$ and $B$. Hence, when $A$ was true then B was false. In light of that, they decided to keep supportive to Chesbrough's (2003) idea. They admitted that Chesbrough (2003) had popularized the OI concept and it reached many organizations successfully compared to other innovation concept approaches (from R\&D) before. They reminded though, "...the Ol concept is not a panacea. Instead, it should be treated as work in progress" ( $p$. 731). Therefore, there was no need to replace the concept and it would be better to support.

Last but not least, both Chesbrough (2003) and Trott \& Hartmann (2009) discussed future issues to be resolved. Chesbrough (2003) revealed about funding, generating, and commercializing innovation. He discussed several funding alternatives to finance innovation and types of innovation that could be chosen. He also discussed about how to commercialize the innovation outcomes. After six years of OI introduction, Trott \& Hartmann (2009) found out that most OI models were developed using linear model based on some established independent variables to dependent variables without presenting feedback relationship. They argued that the forthcoming innovation models should rely on more dynamic relationship, i.e. back and forward, feed and forward mechanisms of which they called Cyclic Innovation Model (p.729). They also notified concern about knowledge leakage that may affect organization's competitive advantage and sustainability. Although the company had opened up the flow of knowledge to other companies, resistance could emerge from internal companies by tightening, reducing and limiting the flow of free knowledge to and from the company. These retention actions could inhibit and limit the OI process.

\subsection{Discussion: Emerging of research topics}


Firstly, position of this paper was in favor of both papers. It did not reject Ol concept nor against the six principles upon. The author agreed that OI had become a standardized innovation concept in many organizations. the author also found that the points of objection presented by Trott \& Hartmann (2009) also had strong logic, though less theoretical support. In fact, Chesbrough (2003) might be somewhat a bit exaggerated when making these six different principles. Anyhow, both papers in general had pointed out that Ol could not be avoided and, instead, it should be used for the benefit of the organization. Currently, OI had attracted significant interest, it had stimulated the publication of hundreds of articles over the course of the last decade. So, both papers were correct by stating that OI was more important and should be accepted (Chesbrough 2003) although the dichotomy term was not entirely correct (Trott \& Hartmann 2009). Nevertheless, this discussion would be focused on potential issues raised by both papers and how these issues had been resolved or pending at this time. Also, some additional points of view on several subjects that believed would improve the offered Ol concept were added during the discussion.

\subsection{Theoretical concept of OI}

Initially analyzed from a wholly theoretical perspective, subsequent research on Ol subject had added focus in qualitative case studies and, empirical (Schroll \& Mild 2012). Their literature study revealed two types of innovation determinants related to Ol adoption, i.e.: market based and organizational based. Interestingly, these two determinant types represented both internal (or $\mathrm{Cl}$ ) and external (or $\mathrm{Ol}$ ) types of innovation. It could be inferred that innovation could be started both from internal and external. This could be further interpret as concluded by Trott \& Hartmann (2009) that $\mathrm{Cl}$ and OI represented two extreme sides where those two sides could combine to create innovation, or one side was being more dominant than the other, or both sides was equally being the cause of innovation. Table 1 detailed those determinants.

In our opinion, however, it was more important to find out why an organization innovate, to find out what was the motivation under the innovation, to see how the innovation was being held and what stage did the innovation should start. It can be argued that being able to exist sustainably in a long term is a fundamental issue for organizations (or companies). Organizations strive to survive in the midst of competition and they need to adapt and change constantly. To enable of doing that, organizations should continuously innovate their product/services or improve their processes in various level of organization. All improvement steps were classified as innovation. Therefore, it could be said that innovation was the key to create changes for survival effort. At macro level, Innovation was also a key factor for economic growth and to enhance industry competitiveness. Governments, especially in developed countries, had actively intervened in designing and implementing economic policies that focused on a more dynamic environment of innovation for decades. Today, innovation was the determinant of improving the economy based on local and state competitiveness (Vega-jurado, Juliao- 
esparragoza, Paternina-arboleda \& Velez 2015). Innovation at the macro level was considered as a way out to create sustainable economic activity and it reflected to the micro level a.k.a. organization (or corporate) level (Ren \& Dewan 2015).

Table 1. Determinants of OI

\begin{tabular}{l|l}
\hline \multicolumn{2}{c}{ Determinants types } \\
\hline Organization based & Market based \\
\hline R\&D intensity (both) & industry characteristic (undetermined) \\
firm size $(+)$ & technology level $(+)$ \\
strategic breadth and diversification $(+)$ & industry hostility $(+)$ \\
geographic proximity $(+)$ & technological turbulence $(+)$ \\
technology aggressiveness (both) & industry speed $(+)$ \\
design capabilities $(+)$ & market uncertainty $(+)$ \\
short term orientation $($ both) & transaction rate $(+)$ \\
customer orientation $(+)$ & \\
rising development cost $(+)$ & \\
firm age (undetermined) & \\
\hline
\end{tabular}

Source: Compiled from Schroll \& Mild, 2012

Unfortunately, it was noted that both Chesbrough (2003) and Trott \& Hartmann (2009) were lacking of theoretical structure when they presented their ideas. There was no presence of strong theoretical framework supporting about why OI was needed or why they finally crossed their own line and backed up the OI idea. Although their critics on the principles seemed legitimate, the absence of strong theoretical could lead into endless debate.

Some basic organization theories could be provided explanation for motivation to innovate at organization level. For example, resource dependence theory (RDT) focused on controlling the critical external resources of organization to improve competitiveness. Efficiency theory focused on innovation to achieve organization's economies of scale for its sustainability. Population-focused ecological theory (population ecology) looked innovation as improvement in its organizational selection mechanisms. Resource based view (RBV) theory hold out innovation concept about selecting and establishing specific internal resources that valuable to organizations and provided supports the company's long-term competitive advantage as a result (Ulrich \& Barney 1984). These important resources were categorized as valuable, rare, imitable, organized (VRIO). Knowledge based view (KBV) focused on knowledge as a valuable resource of an organization (Hedlund 1994). In KBV perspective, knowledge was the VRIO. Currently, researchers also discussed the occurrence of innovation in the organizational context in the framework of social network theory (SNT), forming alliance from weak ties to strong ties (Granovetter 1973; Vasudea \& Anand 2011; Mamavi, et al. 2015; Kozan \& Akdeniz 2014; Suarez 2005). SNT predicted that collaboration was 
deemed necessary and the strength of an organizations in a network was determined by their position in the network and how they utilized the position as bridge of structural gaps between two networks (Tiwana 2008). Hence, these organizational theories could explain motivation of doing innovation, either closed or open innovation.

The SNT stated collaboration occurred at any point along the continuum line between strong ties to weak ties. The passion for sharing within the network formed the basis of collaboration and the position of the organization in the position of the structural gap between the two networks so that the organization gained competitive advantages (Burt 2004). Granovetter (1973) disclosed the role of weak ties to gain information diversification and will bring more benefit companies rather compared strong ties collaboration. Vasudea \& Anand (2011) revised findings from Granovetter (1973) by stating the existence of inverted $U$ relationship against the weak ties position in knowledge utilization. They found out that more weak ties lead to inefficiency and counterproductive to the development of corporate knowledge. This finding was consistent with empirical study from (Shin et al. 2016) of which they found inverted $U$ relationship among horizontal and vertical partnership in Korean biotech companies. Suarez (2005) examined the role of strong ties in corporate strategic decisions, particularly through the selection of technologies that companies will use. He observed that the dominance of strong ties could provide an advantage in making decisions quickly and strategically valuable for the company. Kozan \& Akdeniz (2014) examined the role of strong ties in the growth of small and medium enterprises (SMEs) and specifically they negated the weak ties role in the growth of SMEs. They argued that weak ties played a role in sustainable growth while strong ties played a role in the early business establishment. Mamavi, et al. (2015) conducted a comparative study of the impact of strong ties vs. weak ties towards the capability of alliance management. They found out both ties had a more or less equivalent effects, which implies support for the findings of Vasudea \& Anand (2011) as well as Kozan \& Akdeniz (2014). Table 2 presented the conclusion of some organizational theory towards the direction of innovation.

It could be argued from Table 2 that organizational theory dominantly supported the Ol concept and only RBV and efficiency were in favor of $\mathrm{Cl}$. Thus, it was not surprising that $\mathrm{Ol}$ concept had been raising dramatically over years and left $\mathrm{Cl}$ concept far behind. Most organizational theories, in their explanation, imposed environment (or externalities) as factors that should be considered to achieve organization goal (s). They raised concern about how to behave and how to play the game within organization's population and environment. It could be agreed upon organizations should innovate and the best way to do that was utilizing themselves together with their environment. In light of that, support for both Trott \& Hartmann (2009) and Chesbrough (2003) were found.

Table 2. Organizational theories and innovation direction 


\begin{tabular}{c|l|c}
\hline $\begin{array}{c}\text { Organizational } \\
\text { Theory }\end{array}$ & \multicolumn{1}{|c|}{ Purpose } & $\begin{array}{c}\text { Direction to } \\
\text { innovate }\end{array}$ \\
\hline RDT & maximize organizational power & OI \\
Efficiency & maximize organizational efficiency & Both \\
Population & organization survival & OI \\
RBV & Acquire VRIO (Valuable, Rare, & CI \\
& Imitable, Organized) & OI \\
KBV & Knowledge as VRIO & OI \\
SNT & Connection as VRIO & \\
\hline
\end{tabular}

Chesbrough (2003) had indicated that knowledge became one critical factors in OI and this lead us to understanding that knowledge became VRIO and it was instrumental for generating innovation in companies regardless company's owned technology or other attributes (table 1). If the necessary knowledge was not available within companies, they shared the knowledge resource with their externalities and they needed to establish more intense communication between them. Such communication gave birth to the concept of cooperation and collaboration (SNT) (Gulati 2008). SNT classified the closeness and the effectiveness of such collaborations were reflected by the closeness defined in weak ties and strong ties. The more they communicated each other, the more they were closer into each other (i.e. building and establishing a strong tie) (Tiwana 2008). Continuum between strong ties and weak ties was used to define collaboration quality among organizations, either in strong ties favor (Mamavi, et al. 2015; Un \& Asakawa 2015; Suarez 2005) or weak ties favor (Granovetter 1973; Kozan \& Akdeniz 2014; Vasudea \& Anand 2011) or even interaction between the two ties (Mamavi, et al. 2015; Tiwana 2008). Findings from various studies above showed conclusive evidence that the existence of strong ties and weak ties would change dynamically over time in collaboration and their role were not mutually exclusive nor causal effect. Thus, there was nonlinear process as suspected by Trott \& Hartmann, (2009).

Some interesting research topics about strong and weak ties emerged. For example, research on the strongest potential ties (weak ties vs. weak ties) to generate innovation would be interesting as had been indicated by Chesbrough (2003) too. Another topic was to investigate interchange dynamic process between strong ties and weak ties relationship along the course of the alliance. This would extend the issue from Trott \& Hartmann (2009) of which they indicated that the innovation processes was not straightforward and linear processes, there were also feedback to be included. The potential interchange between the two extremes indicated back and forward relationship between corporations and their collaboration partners as well as proof that the collaboration was not a linear process.

\subsection{Implication to Collaboration and Alliance}


Un \& Asakawa (2015) undertook research on collaboration among corporations (represented by $R$ \& $D$ departments) with their externalities from process innovation domain. Their study took further steps to investigate process innovation which was more subtle and more intangible than product/service innovation (table 3 ). They argued that collaboration also had a positive impact on process innovation. They used four forms of corporation externalities introduced in their research, i.e. suppliers, universities, competitors, and customers. They introduced two dimensions to segregate the externalities, i.e. knowledge distance dimension (far and close) and technology similarities. Suppliers and competitors were externalities having close relationships with companies while universities and customers were externalities with far-reaching relationships with companies. Second, network location (upstream and downstream) of the organization. Suppliers along with universities were classified as companies' upstream externalities (input to company) and competitors along with customers were classified as companies' downstream externalities (output from companies). They hypothesized that the performance of process innovation between the alliance's $R$ \& D collaboration with suppliers $(\mathrm{H} 1)$ would be greater than that of the university $(\mathrm{H} 2)$ would be greater than competitors $(\mathrm{H} 3)$ would be greater than customers $(\mathrm{H} 4)$. In short: $\mathrm{H} 1>\mathrm{H} 2>\mathrm{H} 3>\mathrm{H} 4)$. Their result showed statistical test support on the dominance of the role of downstream externalities $(\mathrm{H} 1$ and $\mathrm{H} 2)$ against upstream externalities but they failed to find signification support to the upstream externalities themselves.

Table 3. Product Innovation vs. Process Innovation

\begin{tabular}{|c|c|c|}
\hline Dimension & Product innovation & Process innovation \\
\hline $\begin{array}{l}\text { objective of innovation } \\
\text { competitive impact } \\
\text { valuation of innovation } \\
\text { degree of novelty } \\
\text { codifiability of } \\
\text { knowledge } \\
\text { location of knowledge }\end{array}$ & $\begin{array}{l}\text { novelty } \\
\text { price } \\
\text { external } \\
\text { radical, exploration } \\
\text { clear, concrete, explicit, higher } \\
\text { technological, separable, } \\
\text { independent }\end{array}$ & $\begin{array}{l}\text { efficiency } \\
\text { cost } \\
\text { internal } \\
\text { incremental, exploitation } \\
\text { unclear, obscure, tacit, lower } \\
\text { organizational, systemic, } \\
\text { interdependent }\end{array}$ \\
\hline
\end{tabular}

Source: Summarized from Un \& Asakawa, 2015, p.140

Thus, their study had not been able to confirm findings from other studies in collaboration topics for innovation in the eyes of product innovation, such as the dynamics of vertical and horizontal collaboration of companies (Shin et al. 2016) and corporate growth through collaboration (Mamavi, et al. 2015). This result could also be inferred that there was incompatible model between product innovation and process innovation. Similar result could not be expected when the two modes of innovation using same model.

Weak result from Un \& Asakawa (2015) clearly showed that an established model of product innovation could not be simply imitated to process innovation 
without proper adjustment. Furthermore, recent work from Fang, Liao, and Xie (2016) and Gao (2015) indicated potential research works on mathematic modelling to verify vendor's credential and applying risk mitigation in long term collaboration contact. Some exploratory research work to find out relevant variables would be interesting and challenging projects to do.

\subsection{Implication to funding and commercialization}

We noted concern from Chesbrough (2003) about funding and commercializing innovation. In funding scheme, he proposed two modes of funding scheme: (1) innovation investor including venture capital, angel investor, corporate R\&D budget, private equity investors, and other similar business models. These types of investor focused on the preliminary stage of innovation and mostly they were risk taker. (2) Innovation benefactors including any investors focused on early stage of research discovery. The benefactors looked at promising result at early stage to find out its suitability with their own interest. Hence, the second ones were more risk averse. In commercializing innovation, he also proposed two types of organizations: (1) innovation marketers specializing in profitably market ideas. It focused on developing ability to recognize current and potential needs in the market and brought the idea in-house. (2) Innovation one-stop center providing more comprehensive innovation product and services. It functioned as intermediary between innovators and user of innovation. Figure 1 below showed conceptualization from Kasatova, Vagizova, \& Tufetulov (2016) mixed with Chesbrough's model (2003) about funding and commercialization. Kasatova et al. (2016) presented their descriptive research work about the end to end innovation process from biotechnology innovation product. They proposed four main stages of an innovation process. The first two stages on the left was the stage of which Kasatova et al. (2016) stated its focus was to find funding to generate innovation idea and supporting research. These stages were relevant to Chesbrough's model (2003) about funding as well as commercialization.

It was assumed that innovation investors were people (or institution) willing to fund as incubation stage (or basic research) where everything was still unclear (exploration area). The second innovation benefactors were placed in investment stage (or applied research) where at this point investors could see potential application that match with their need. This paper also added period of investment. It can be argued that at incubation stage, investors should look at long period to get the benefit so that it was a riskier investment compared to the investment stage which was shorter period so that it was less risky. The next two stages on the right was the stage of which Chesbrough's model (2003) defined as commercialization as well as the model of Kasatova et al. (2016). At these stages, two organization were added form models from Chesbrough (2003). 


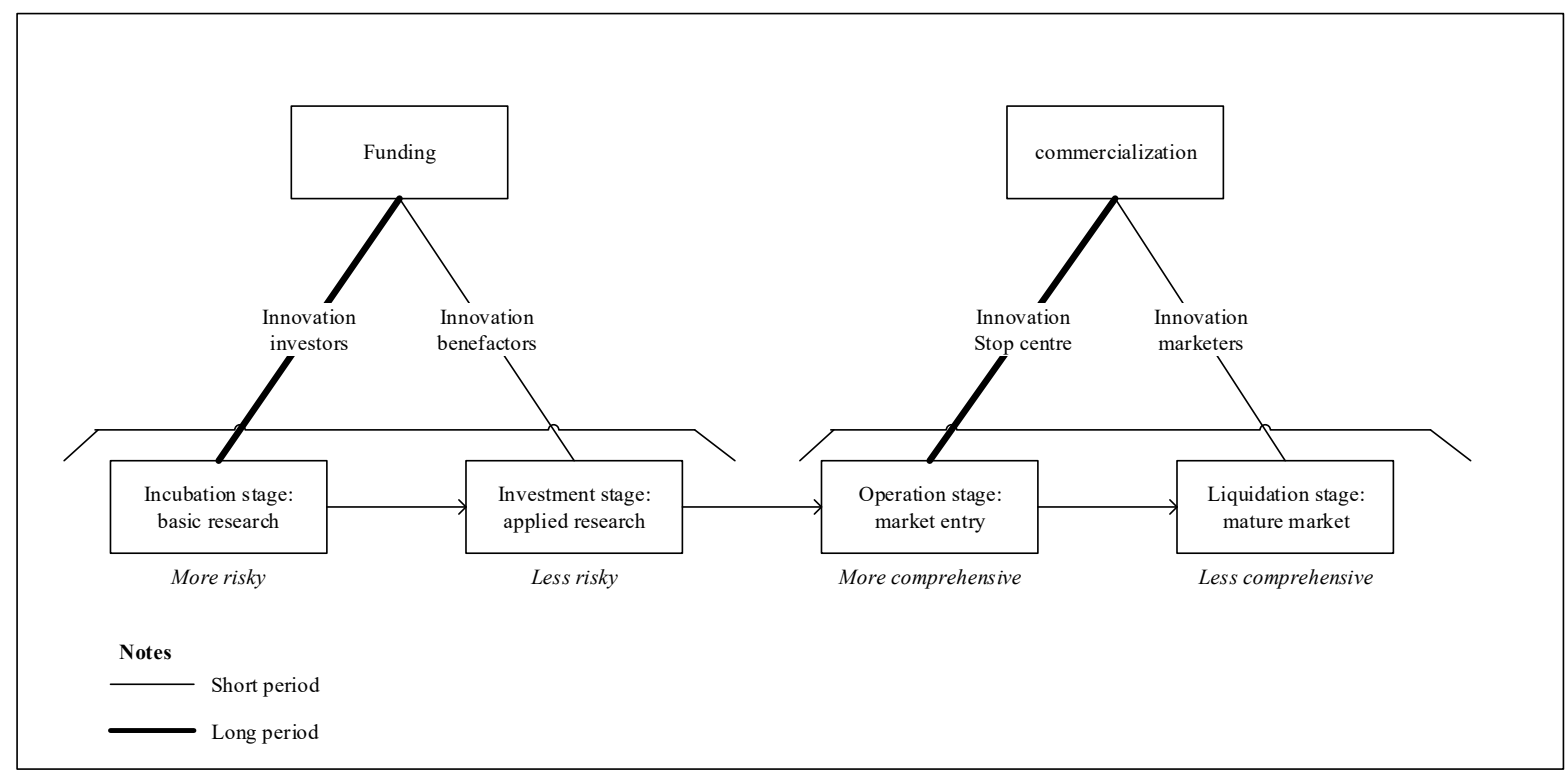

Figure 1. End to end innovation process

(modified from Kasatova et al., 2016, p.194)

It was argued that innovation stop center should be placed in the operation stage which containing more options to explore the innovation result and found the best way to enter the market. The center should determine which outcomes should be followed up, what strategic product (or strategic service) should be undertaken, and so on. Given that, the period should be long term with more comprehensive than the other model. Innovation marketers, as stated in Chesbrough's model (2003) focused more on deliver a profitable product or service to the market. It was about serving established market and maintained its sustainability. Thus, as stated before, this model was less comprehensive and was intended to serve in a shorter period. Further research to investigate the best fitted funding and commercialization mechanism as well as to find out the most suitable organization types would be challenging subjects to be explored with.

\subsection{Implication to intermediary role}

Furthermore, this paper also noted that the role of intermediary agent between innovators and innovation users had become increasingly critical. The Ol concept shifted from two parties into three parties (with intermediary roles) and some research works had tried to identify the role of the intermediary agents in innovation. Recent research from Dutt, Vidal, \& Mcgahan (2016) revealed four intermediary agents functioned differently. They were academic, non-government organization (NGO), government, and private. Their role was to provide physical infrastructure (such as financial matter and infrastructure) and non-physical infrastructure (competence, knowledge). 
Table 4 summarized the result. It showed that the academic and NGO roles were primarily in non-physical subjects, namely capability enhancement through training (NGO) and consultation (academic) activities. Training presupposed increased capability at a more basic level, i.e. it occurred when the company started a new business or in incubator form. Consultation, on the other hand, presupposed enhanced capability at a more advanced level, for example in product/service improvement or new product/service development. In physical subjects, academic role provided physical infrastructure, such as the provision of land or buildings while private played a role in the financial aid. Interestingly, Dutt et al. (2016) failed to support the role of government as an intermediary agent in which the government could intervene in infrastructure, financial support, and even capability improvement. In addition, Hallen \& Rosenberger (2014) investigated the role of these intermediaries to the social defense mechanism. They claimed that the more local investors, the more company tried to engage into collaboration. Their relation was stronger when they were more local and brought less secrecy among them. If the finding from Hallen \& Rosenberger (2014) was combined with agency types and their roles in promoting better innovation performance from Dutt et al. (2016), better result with better explanation might be achieved. The nonsignificance role of government as intermediary agent was also an alarming signal. Recent work from Biegelbauer (2016) described the role of government to provide policy and law. Government also could function as balancer in the market (Weigelt \& Shittu 2016). Thus, it can be argued that government should function as one of the intermediary agents in innovation and their role were even more critical since they were also expected to produce policy that lead to governance system.

Given that, some topics for future research also emerged from this discussion. First, future research could put effort to combine geographic concept within agencies would be potential to improve the intermediary roles. The intermediary also, once again, confirmed suggestion from Trott \& Hartmann (2009) about non linearity existence in innovation process. By using intermediary, there would be two ways communication facilitated by the agent. Feedback and suggestion also applied in this case. The communication model among these three parties would also be interesting subject to be investigated. Last but not least, the role of each intermediary agent, especially government, was still in large.

Table 4. Intermediary role

\begin{tabular}{|l|c|c|c|c|}
\hline \multirow{2}{*}{ Types } & \multicolumn{4}{|c|}{ Area of connectivity } \\
\cline { 2 - 5 } & \multicolumn{3}{|c|}{ Physical } & \multicolumn{2}{c|}{ non-physical } \\
\cline { 2 - 5 } & Infrastructure & Finance & Training & Consultation \\
\hline Private & & $\mathrm{x}$ & & \\
\hline Academic & $\mathrm{x}$ & & & $\mathrm{x}$ \\
\hline NGO & & & $\mathrm{x}$ & \\
\hline Government & & & & \\
\hline
\end{tabular}

Source: Summarized from Dutt et al., 2016 


\subsection{Implication to organizational mechanism}

In most Ol cases, innovation in established organization started with small groups with initiatives, or using business incubator or entrepreneurship to do innovation in small medium enterprises (SMEs) (Indarti \& Wahid 2013; Curry \& Donnellan 2014; Shibeika \& Harty 2016; Liao et al. 2003). For example, Shibeika \& Harty (2016) investigated innovation process in construction company starting from small group to set a standardized processes and continued with the next innovation processes and so on. Curry \& Donnellan (2014) investigated innovation process in Intel which started with small group to set big goals and to achieve subgoals in each stage. Entrepreneurship had become the best practice form to execute innovation due to its agility, flexibility, and creativity facing challenges (Indarti \& Wahid 2013). Creativity was recognized as source of innovation and it was important to setup friendly environment to boost creativity (Yström et al. 2015) and resulted in innovative behavior led to innovation performance (Omri 2015). On top of all of these factors, the role of leader in innovation was also become increasingly important. Caridi-zahavi, Carmeli, \& Arazy (2016) described the role of leader to connect people not only within organization but also between organizations. The connectivity was vital to integrate knowledge in and outside organization to ensure successful innovation. It was noted that Chesbrough (2003) had indicated the tendency to start innovation from small group with high creativity but he failed to notify the role of leader to nurture such creativity. It was also believed that the connection could reduce potential retention to Ol as the leader could communicate the changes to all of the organization people. Some case study in business process reengineering had evidenced on this matter, such as BPR2 (Khosravi 2016) and affordance mechanism (Scarbrough et al. 2015). The communication system, either formal and informal, would be vital in responding to Trott \& Hartmann's concern (2009). This also worth to be investigated further.

\subsection{Implication to security and governance system}

Chesbrough (2003) also raised concern about intellectual property rights was prone due to the existence of Ol. To what extent Ol could be granted access to company's intellectual property and knowledge. This review found out that data security issues remained a critical issue of the day, specifically when the data were transferred into digital form and made technology as one critical major infrastructure in innovation. Culnan \& Williams (2009) argued that violations of data security were serious and could affect the level of trust of externalities to the company. They presented cases of data breaches at two companies, the ChoicePoint and TJX. Both companies suffered significant material and nonmaterial losses due to the data breach. To mitigate the threat, Culnan \& Williams (2009) proposed that data security should be an integral part of the company's business processes. They proposed four programs that could help prevent this data breach. First, to create a culture of data confidentiality in the organization. To do so, they argued the initiative should start from top management. Examples must be created from the leader. Secondly, to implement good governance of which was 
in favor of secrecy. Organizations needed to develop their governance system to ensure that the rules and controls were in place. Third, to establish an ethics committee whose members were coming from managers across all organizational units to deal with technical and day to day issues. This committee was in charge of ensuring that secrecy-oriented governance was carried out in accordance with the rules. Finally, to develop a more personal approach to deal with data usage and maintenance, i.e.: how managers treat their customer data like treating their data (managers) themselves. Thus, the data processing in the organization should also be treated individually and became valuable data. Culnan \& Williams (2009) convinced that data confidentiality management will be more effective when the four programs had been in place within companies.

According to the above cases, it could be concluded that trust between two parties when starting collaboration (or becoming alliance) was instrumental. Lack of understanding and knowing the characteristics of the potential partner would hinder the collaboration process and it would be difficult to apply SNT collaboration scheme in such distrust situation. To that end, the good credential of one organization became paramount in establishing a good collaboration. Building such a good reputation should started within the organization itself by showing the good intentions to the others Showing good intention could be reflected from willingness to accommodate potential partner's interest (Chang et al. 2008). Specifically for OI case, how to carry out responsible innovation that brought goodness was the key message. Voegtlin \& Scherer (2017) argued that every innovation project should meet three goals simultaneously, namely greater benefits for people, the planet (environment), and economic benefits. And while setting those aims, the innovation outcomes should not to threaten the human life and should improve human life. Some interesting topics emerged from this discussion. For example, research in the field of data security governance was important to foster trust among collaborating parties. By nurturing trust antecedents, the result could support the creation of bonds within the network of alliances. Research in the field of ethics was also still in large to be explored. Given the dynamics that occurred in the OI model, it was believed code of ethics was required to provide some ground rules to deal with end to end innovation process.

\subsection{Collection of future research topics}

From all the discussion above, this paper pointed out some interesting research topics to be explored in the future. Some of the topics also intertwined with topics identified by Hossain (2013) proved the relevant issue(s) were still outstanding. However, we also identified some new potential research topics as well. Six main topics were composed according to the discussion format. First, collaboration and closeness of the relationship. Finding explanation of how SNT and KBW could explain more about intersection between strong ties and weak ties and at the same time nurturing collaboration effort. Second, collaboration model for both product and process innovation. Developing the best suited collaboration model for each innovation types. Third, funding and innovation commercialization. 
The issue about how one innovation could be funded, at which stage and what was the best strategy to be used (mechanism). What kind of the best suit organization to do the commercialization (institution)? Fourth, the development of an intermediary role as an extension of Ol activity. Finding out which agent and what its fittest role in collaboration. Confirming how the mechanism on each agent to organization and how to utilize the agent's in favor to organization's goal. Fifth, organizational mechanism. Finding more contribution from organizational mechanism such as organizational structure, leadership, business model (entrepreneurship and business incubator) and creativity that contribute to innovation. Sixth, security and governance system. Defining innovation that brought goodness to stakeholders, developing governance system as well as code of conduct to organizations, building trust to potential alliances. The potential topic list goes on. Figure 2 depicts the group of the topics.

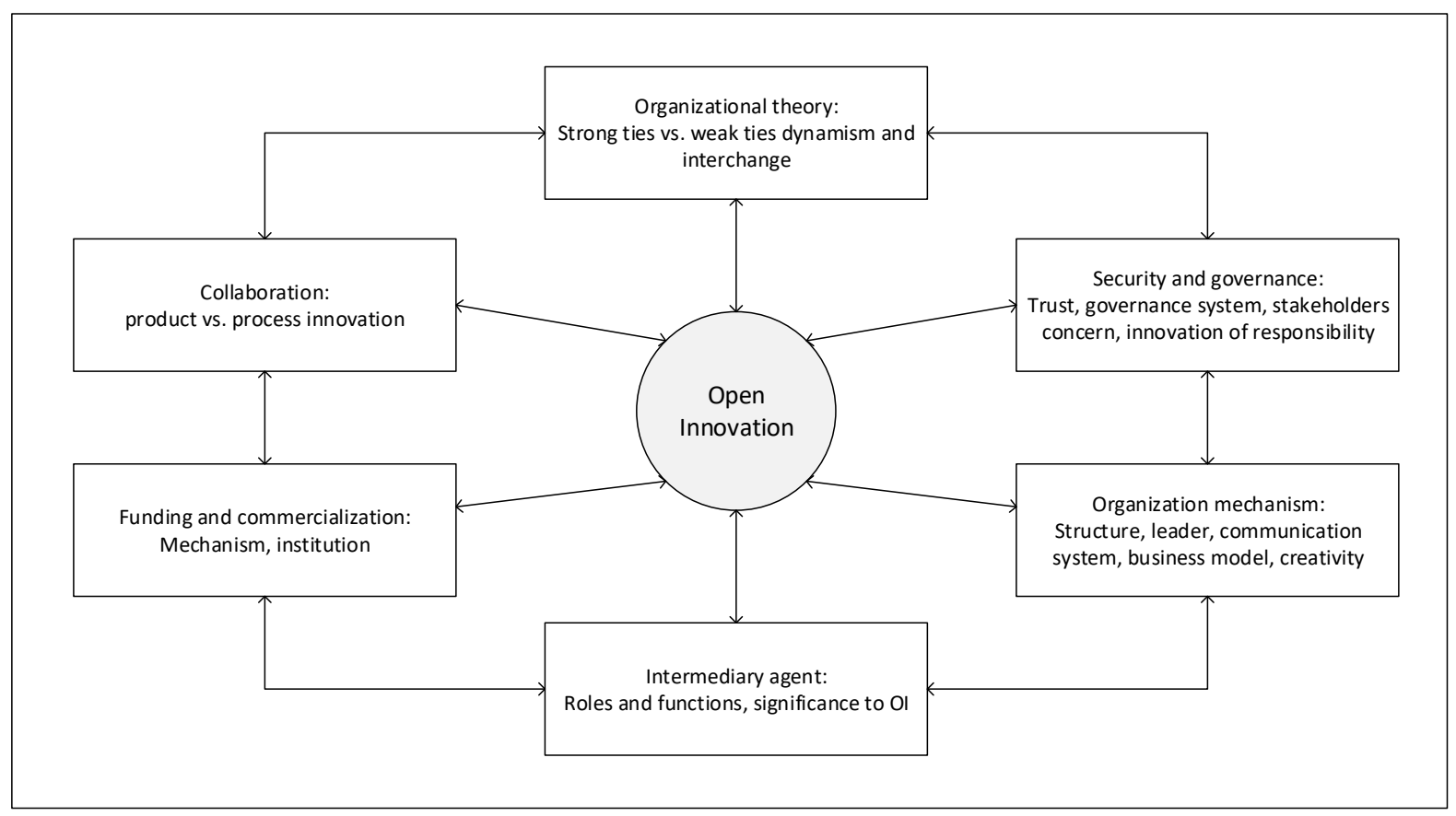

Figure 2. Group of potential future research topics

All of these potential topics could cross one with the others. Organizational theories, for example, could use collaboration topic for its implementation factor. Or, funding and commercialization could group together with the role and function of one or couple intermediary agents. 


\section{CONCLUSION}

This review had discussed the six principles given by Chesbrough (2003) segregating $\mathrm{Ol}$ and $\mathrm{Cl}$ and at the same time discussed the critics from Trott \& Hartmann (2009) about the six principles. This paper did not find strong evidence to reject the Ol concept and noted that OI had been widely accepted and applied in many companies in many countries. Given that, the concept itself was reliable. Nevertheless, this review focused on the current follow-up of some of the concerns raised by both papers (Trott \& Hartmann 2009; Chesbrough 2003). A number of potential research topics emerged as a result.

Finally, this review was an excavation of ideas for follow-up research in the field of OI. Indeed, in preparing empirical research on the proposed topics, a number of technical issues would arise; such as the development of variables, the relationship definition between variables, the measurement of variables, data collection together with data process and data analysis. However, this review did not address to handle such these issues and they became homework for prospective researchers. Albeit all the potential research works had been discussed above, this paper acknowledge limitation of empirical works yet to be done and it is believed the road ahead still goes on.

\section{REFERENCE}

Biegelbauer, P., 2016. How different forms of policy learning influence each other: case studies from Austrian innovation policy-making. Policy Studies, 37(2), pp.129-146.

Burt, R.S., 2004. Structural holes and good ideas. American Journal of Sociology, 110(2), pp.349-399.

Caridi-zahavi, O., Carmeli, A. \& Arazy, O., 2016. The influence of CEOs ' visionary innovation leadership on the performance of high-technology ventures: The mediating roles of connectivity and knowledge integration. Journal of Product Innovation Management, 33(3), pp.356-376.

Chang, L., Cheng, M. \& Trotman, K.T., 2008. The effect of framing and negotiation partner's objective on judgments about negotiated transfer prices. Accounting, Organizations and Society, 33, pp.704-717.

Chesbrough, H.W., 2003. The era of open innovation. MIT Sloan Management Review, 44(3), pp.34-41. Available at: http://dialnet.unirioja.es/servlet/articulo?codigo $=2316408$.

Culnan, M.J. \& Williams, C.C., 2009. How ethics can enhance organizational privacy: Lessons from the ChoicePpoint and TJX data breaches. MIS Quarterly, 33(4), pp.1-15. 
Curry, E. \& Donnellan, B., 2014. Implementing sustainable IT strategy: case of Intel. Journal of Information Technology Teaching Cases, 4(1), pp.41-48. Available at: http://dx.doi.org/10.1057/jittc.2014.2.

Dutt, N., Vidal, E. \& Mcgahan, A., 2016. How open system intermediaries address institutional failures: The case of business incubators in emerging-market countries. Academy of Management Journal, 59(3), pp.818-840.

Fang, C., Liao, X. \& Xie, M., 2016. A hybrid risks-informed approach for the selection of supplier portfolio. International Journal of Production Research, 54(7), pp.2019-2034.

Gao, L., 2015. Long-Term Contracting: The Role of Private Information in Dynamic Supply Risk Management. Production and Operations Management, 24(10), pp.1570-1579.

Granovetter, M.S., 1973. The strength of weak ties. American Journal of Sociology, 78(6), pp.1360-1380.

Gulati, R., 2008. Network location and learning: The influence of network resources and firm capabilities on alliance formation. Strategic Management Journal, 20(5), pp.397-420.

Hallen, B.L. \& Rosenberger, J.D., 2014. How do social defenses work? A resource dependece lens on technology ventures, venture capital investors, and corporate relationships. Academy of Management Journal, 57(4), pp.1078-1101.

Hedlund, G., 1994. A model of knowledge management and the $\mathrm{N}$-form corporation. Strategic Management Journal, 15, pp.73-90.

Hossain, M., 2013. Open innovation: so far and a way forward. World Journal of Science, Technology and Sustainable Development, 10(1), pp.30-41.

Indarti, N. \& Wahid, F., 2013. How do Indonesian industries perceive universityindustry collaboration? Motivations, benefits and problems. International Journal of Technology Transfer \& Commercialisation, 12(1), pp.157-171.

Kach, A., Azadegan, A. \& Wagner, S.M., 2015. The in fluence of different knowledge workers on innovation strategy and product development performance in small and medium-sized enterprises. International Journal of Production Research, 53(8), pp.2489-2505.

Kasatova, A.A., Vagizova, V.I. \& Tufetulov, A.M., 2016. Stages of biotechnology commercialization in the system of interaction between financial and innovative industrial structures. Academy of Strategic Management Journal, 15(Special Issues 1), pp.191-198.

Khosravi, A., 2016. Business process rearrangement and renaming: A new approach to process orientation and improvement. Business Process Management Journal, 22(1), pp.116-139. 
Kozan, M.K. \& Akdeniz, L., 2014. role of strong versus weak networks in small business growth in an emerging economy. Administrative Sciences, 4, pp.35-50.

Liao, J., Welsch, H. \& Stoica, M., 2003. Organizational absorptive capacity and responsiveness: An empirical investigation of growth-oriented SMEs. Enterpreneurship Theory and Practice, Fall, pp.63-86.

Mamavi, O., Meier, O. \& Zerbib, R., 2015. Alliance management capability: the roles of alliance control and strength of ties. Management Decision, 53(10), pp.2250-2267.

Nonaka, I., 1991. The knowledge creating company. Harvard Business Review, 69, pp.96-104.

Omri, W., 2015. Innovative behavior and venture performance of SMEs: The moderating effect of environmental dynamism. European Journal of Innovation Management, 18(2), pp.195-217.

Ren, F.E.I. \& Dewan, S., 2015. Industry-level analysis of information technology return and risk: What explains the variation? Jpurnal of Management Information Systems, 32(2), pp.71-103.

Scarbrough, H., Robertson, M. \& Swan, J., 2015. Diffusion in the face of failure: The evolution of a management innovation. British Journal of Management, 26, pp.365-387.

Schroll, A. \& Mild, A., 2012. A critical review of empirical research on open innovation adoption. Journal fur Betriebswirtsch, 62, pp.85-118.

Shibeika, A. \& Harty, C., 2016. Diffusion of digital innovation in construction: a case study of a UK engineering firm. Construction management and economics, 33(5/6), pp.453-466.

Shin, K., Kim, S.J. \& Park, G., 2016. How does the partner type in R\&D alliances impact technological innovation performance? A study on the Korean biotechnology industry. Asia Pacific Journal of Management, 33(1), pp.141-164.

Suarez, F.F., 2005. Network effects revisited: The role of strong ties in technology selection. Academy of Management Journal, 48(4), pp.710-720.

Tiwana, A., 2008. Do bridging ties complement strong ties? An empirical examination of alliance. Strategic Management Journal, 272(April 2002), pp.251272.

Trott, P. \& Hartmann, D.A.P., 2009. Why "Open Innovation" is old wine in new bottles. International Journal of Innovation management, 13(4), pp.715-736.

Ulrich, D. \& Barney, J.B., 1984. Perspectives in organizations: Resource and dependence, efficiency, population. Academy of Management Review, 9(3), pp.471-481. 
Un, C.A. \& Asakawa, K., 2015. Types of R\&D collaborations and process innovation: The benefit of collaborating upstream in the knowledge chain. Journal of Production and Innovation Management, 32(1), pp.138-153.

Vasudea, G. \& Anand, J., 2011. Unpacking absorptive capacity: A study of knowledge utilization from aliance portfolios. Academy of Management Journal, 54(3), pp.611-623.

Vega-jurado, J. et al., 2015. Integrating technology, management and marketing innovation through open innovation models. Journal of Technology Management and Innovation, 10(4), pp.85-91.

Voegtlin, C. \& Scherer, A.G., 2017. Responsible innovation and the innovation of responsibility: governing sustainable development in a globalized world. Journal of Business Ethics, 143, pp.227-243.

Weigelt, C. \& Shittu, E., 2016. Competition, regulatory policy, and firm's resource investments: the case of renewable energy technologies. Academy of Management Journal, 59(2), pp.678-704.

Yström, A., Aspenberg, H. \& Kumlin, A., 2015. Exploring the creative climate in an open innovation arena. European Journal of Innovation Management, 18(1), pp.70-85. Available at: http://dx.doi.org/10.1108/EJIM-08-2013-0085. 